\section{Editorial Especial'}

\author{
À Regina Maria Giffoni Marsiglia
}

\section{In memoriam}

A Saúde Coletiva brasileira está de luto. Em 16 de julho deste ano tivemos a notícia do falecimento de Regina Marsiglia, que nos deixou nas primeiras horas desse dia. Mulher, companheira, esposa, mãe, avó, amiga, professora, pesquisadora, militante... "Foi alguém tão grande que escrever sobre ela não seria suficiente para abarcar tudo o que representou e continuará representando para todos nós".

Com formação em Serviço Social e Ciências, concluiu mestrado e doutorado em Ciências Políticas, sendo uma das pioneiras na incorporação e atualização desses conhecimentos para o campo da saúde. Regina é referência como educadora e pesquisadora, com várias publicações, e orientadora de diversos trabalhos acadêmicos na área de Saúde Coletiva.

Participou de forma ativa na década de 1970 na construção da Saúde Coletiva brasileira através da atuação militante no Movimento da Reforma Sanitária, contribuindo substantivamente com seus ensinamentos e reflexões, sempre atenta e preocupada com a organização e qualificação das práticas de saúde. Nessa linha, atuou na Associação Brasileira de Saúde Coletiva (Abrasco) e foi uma das diretoras da Associação Paulista de Saúde Pública (APSP).

A formação de recursos humanos em saúde sempre foi uma área de interesses acadêmicos bastante presente em suas preocupações teóricas e metodológicas, seus exercícios da docência e suas observações do trabalho em saúde. Nessa direção, Regina fez parte da constituição e consolidação do Departamento de Medicina Social da Faculdade de Ciências Médicas da Santa Casa de São Paulo (FCMSCSP), bem como do Núcleo de Saúde na Faculdade de Serviço Social da Pontifícia Universidade Católica de São Paulo. Foi diretora do
Centro de Estudos Augusto Leopoldo Ayrosa Galvão (Cealag), liderança do Grupo de Pesquisa Recursos Humanos em Saúde/CNPq, coordenadora do Núcleo Profissões da Saúde do Observa RH-SP/Ministério da Saúde/Opas e responsável pela implantação Projeto de Integração Docente-Assistencial (Pida) e do Programa de Reorientação da Formação dos Profissionais de Saúde (Pró-Saúde), do Ministério da Saúde/Ministério da Educação, na FCMSCSP. Recentemente tinha assumido a Coordenadoria da Extensão Acadêmica da FCMSCSP.

Inúmeras são as contribuições, participações e iniciativas da Profa. Regina Marsiglia no campo da Saúde Coletiva e, particularmente, na educação profissional, orientando e qualificando o necessário enfrentamento da integração ensino e serviços de saúde. Nesse sentido, sempre reconheceu e valorizou, apoiando como educadora e pesquisadora a capacidade dos profissionais de saúde na produção de saberes, inovações e qualificações das práticas decisivas para o cuidado integral em saúde à população.

Nessa perspectiva, Regina incentivou e fez parte da emergência do projeto editorial da Saúde e Sociedade, entendendo-a como uma publicação necessária para ocupar o espaço de incorporação e aproximação do saber e do saber-fazer, da produção da academia e da sistematização problematizadora das práticas de saúde.

A Saúde e Sociedade sempre contou com a presença e a disponibilidade de Regina nos pareceres, nos eventos públicos e nos momentos de reflexão sobre os caminhos editoriais da revista. Portanto, esse editorial é um reconhecimento e forte agradecimento pelo seu legado à Saúde Coletiva.

São Paulo, setembro de 2017.

Nivaldo Carneiro Júnior Editor Associado

\footnotetext{
1 Texto elaborado a partir de DEPARTAMENTO DE SAÚDE COLETIVA; DIREÇÃO DA FACULDADE DE CIÊNCIAS MÉDICAS DA SANTA CASA DE SÃO PAULO. Homenagem à Profa. Dra. Regina Maria Giffoni Marsiglia (19/11/1943 - 16/o7/2017). Notícias FCMSCSP, São Paulo, 28 jul. 2017. Disponível em: <https://goo.gl/4enY8C>. Acesso em 14 set. 2017.
} 


\section{Errata}

No Editorial Especial À Regina Maria Giffoni Marsiglia In memoriam, com número de DOI: 10.1590/So104-12902017263100, publicado no periódico Saúde e Sociedade, 26(3): 611-611, na página 611: Foi solicitado, pelo autor, a inclusão da palavra "Sociais" no $2^{\circ}$ parágrafo do texto: "Com formação em Serviço Social e Ciências Sociais...”.

\section{Onde se lia:}

"Com formação em Serviço Social e Ciências,...”

\section{Leia-se:}

“Com formação em Serviço Social e Ciências Sociais,...” 